\title{
O AMICUS CURIAE NO SUPREMO TRIBUNAL FEDERAL: UMA ANÁLISE SOBRE SEU POTENCIAL DEMOCRÁTICO ${ }^{1}$
}

AMICUS CURIAE AT THE SUPREME FEDERAL COURT: AN ANALYSIS ON ITS DEMOCRATIC

POTENTIAL

Gabriela MERLO

Jose Moisés RIBEIRO

ISSUE DOI: $10.21207 / 2675-0104.2019 .895$

\begin{abstract}
RESUMO
O presente trabalho de iniciação científica possui o objetivo de promover a análise da figura do "amicus curiae" no Supremo Tribunal Federal e como esta pode contribuir de forma a tornar as decisões mais democráticas, principalmente no que se refere às ações de controle concentrado de constitucionalidade. Neste sentido, a metodologia utilizada se deu na forma qualitativa, sendo utilizados os métodos de pesquisa bibliográfica e documental. Dessa forma, é cabível o entendimento no sentido de que o "amicus curiae" possui um caráter democrático o qual se encontra presente na própria definição da figura, sendo potencializado não apenas ao auxiliar o magistrado a proferir uma decisão, como também ao contribuir trazendo novos argumentos referentes ao caso e que possam auxiliar na elucidação do
\end{abstract}

\footnotetext{
${ }^{1} \mathrm{O}$ presente artigo sintetiza a monografia de conclusão da pesquisa, realizada para o Programa Interno de Bolsas de Iniciação Científica (PIBIC 2018-2019) da Faculdade de Direito de Franca (FDF), Franca/SP.

${ }^{2}$ Discente da Faculdade de Direito de Franca (FDF), Franca/SP. Bolsista do Programa Interno de Bolsas de Iniciação Científica (PIBIC 2018-2019).

${ }^{3}$ Possui Doutorado em Direito, pela Universidade Autônoma de Direito (2018), Mestrado em Direito das Relações Econômicas-Empresariais pela Universidade de Franca (2006), Licenciatura Plena em Português pela Universidade de Franca (1999), Graduação em Direito pela Universidade Federal de Uberlândia (1995). Atualmente é professor titular do Colégio Sapiens de Araraquara, do Colégio Positivo de Ipuã, do Colégio COC de Pitangueiras e Diretor do Curso de Expressão de Língua Portuguesa em Franca.
} 
problema. No entanto, alguns obstáculos que a figura enfrenta no ordenamento brasileiro, são o desconhecimento de muitos indivíduos quanto ao seu uso, bem como a necessidade de possuir advogado caso deseje postular voluntariamente como "amicus curiae". Além disso, deve-se buscar trazer argumentos inovadores, tendo em vista que a mera repetição de argumentos já proferidos pelas partes somente protrai o processo.

Palavras-chave: Amicus curiae. Supremo Tribunal Federal. Potencial democrático.

\section{RESUMÉN}

El presente trabajo de iniciación científica tiene el objetivo de provocar un análisis acerca de la figura del "amicus curiae" en el Supremo Tribunal Federal y cómo este ente puede contribuir para que las decisiones sean más democráticas, principalmente en las acciones de control concentrado de constitucionalidad. De esta manera, la metodología utilizada se dio cualitativamente, utilizándose los métodos bibliográficos y documentales. De esta manera, es posible el entendimiento de que el "amicus curiae" presenta un carácter democrático, siendo que el mismo se encuentra presente en la propia definición de la figura. No obstante, esta visión democrática se potencia no solamente con la posibilidad de auxiliar al juez a proferir una decisión, sino también al traer nuevas argumentaciones frente al caso y que contribuyan en la elucidación y comprensión del problema. Sin embargo, algunos obstáculos que la figura presenta en el ordenamiento brasileño son el desconocimiento de la población acerca del uso, la necesidad de haber un abogado cuando se desee postular de manera voluntaria como "amicus curiae" y la necesidad de traer nuevos argumentos, ya que la repetición de argumentos ya dichos por las partes solamente prolonga el proceso y no contribuye para una decisión más fundamentada.

Keywords: amicus curiae; Supremo Tribunal Federal; potencial democrático.

O presente trabalho se insere no âmbito do Direito Constitucional e possui como questão de pesquisa a análise teórica da figura do amicus curiae. Além disso, busca promover uma reflexão acerca de sua natureza democrática, a qual se encontra ressaltada principalmente nas ações de controle concentrado de constitucionalidade julgadas pelo Supremo Tribunal Federal.

Neste sentido, embora a atuação do amicus curiae não se restrinja ao Supremo Tribunal Federal, foi adotada a referida análise como forma de melhor delimitar o objeto estudado, possibilitando um maior aprofundamento da figura sob esta ótica.

Em relação as ações de controle concentrado de constitucionalidade, umas das características mais marcantes reside no fato de ser erga omnes (ou seja, aquilo que for decidido terá repercussão a todos os cidadãos de forma indistinta). Neste sentido, a presença do amicus curiae se faz de fundamental importância, pois possibilita a apresentação de diferentes posições e aspectos a respeito do mesmo tema, fazendo com 
que o magistrado disponha de um maior leque argumentativo ao proferir uma decisão.

Por fim, tendo em vista a ideia desenvolvida por Peter Haberle de que a Constituição deve estar aberta aos intérpretes e haja vista a influência desta teoria para a implantação da figura do amicus curiae no Brasil, buscou-se realizar uma análise da mesma como forma de demonstrar a sua importância para a aplicação do amicus curiae no Brasil.

Para tanto, a metodologia utilizada nesta pesquisa utilizou-se da forma qualitativa, sendo utilizados métodos de pesquisa bibliográfica e documentais. Neste sentido, houve a análise do tema no âmbito do Direito Constitucional, bem como no Direito Processual Civil, servindo como referência os entendimentos doutrinários, jurisprudenciais, bem como as normas supra e infralegais dispostas no ordenamento brasileiro.

\section{ORIGEM}

A origem da figura do amicus curiae $e^{4}$ é muito controvertida, contudo é unânime o entendimento de que não se trata de instituto recente. Para Steven Kochevar (2013, p. 2) o amicus curiae possui a sua existência a partir do direito romano, sendo posteriormente difundido, especialmente em países que adotam o sistema common law.

Segundo Kochevar (2013, p. 8), as possíveis explicações para o crescimento da adoção da figura do amicus curiae no modelo civil law foram as seguintes: a pressão realizada por ONGs para participarem de forma informal como amicus curiae, agindo no sentido de buscar normalizar a atividade deste ente por meio de publicações legais; a influência do direito internacional no direito interno de cada país; e por fim a natural adequação dessa figura com o sistema do civil law, tendo em vista que há maiores possibilidades de intervenção de terceiros nestes ordenamentos.

No que se refere ao Brasil, à existência desta figura no ordenamento brasileiro é relativamente recente, tendo recebido maior destaque a partir de sua introdução no Novo Código de Processo Civil.

\footnotetext{
${ }^{4}$ O presente artigo sintetiza a pesquisa realizada junto ao Programa de Iniciação Científica 2018/2019 da Faculdade de Direito de Franca.
} 
Além disso, não se pode perder de vista que o ordenamento brasileiro também apresenta uma influência advinda do sistema common law. Conforme explica Fredie Didier Júnior (2017, p. 67):

\begin{abstract}
O sistema jurídico brasileiro tem uma característica muito peculiar, que não deixa de ser curiosa: temos um direito constitucional de inspiração estadounidense (daí a consagração de uma série de garantias processuais, inclusive, expressamente, do devido processo legal) e um direito infraconstitucional (principalmente o direito privado) inspirado na família romano-germânica (França, Alemanha e Itálica, basicamente). Há controle de constitucionalidade difuso (inspirado no judicial review estadunidense) e concentrado (modelo austríaco). Há inúmeras codificações legislativas (civil law) e, ao mesmo tempo constrói-se um sistema de valorização dos precedentes judiciais extremamente complexo (súmula vinculante, súmula impeditiva, julgamento modelo para causas repetitivas etc), de óbvia inspiração no common Law.
\end{abstract}

\title{
CONCEITUAÇÃO
}

Conforme Fredie Didier Jr. (2017, p. 588) o amicus curiae caracteriza-se por ser tido como um terceiro que poderá espontaneamente, a pedido da parte ou por requisição jurisdicional, intervir no processo de forma a trazer argumentos e materiais que auxiliem no sentido de aprimorar a qualidade da decisão.

No ordenamento brasileiro não se trata de figura tão nova, tendo em vista que, conforme demonstra Humberto Theodoro Jr. (2017, p. 409), existiam certas leis esparsas e que o Código de Processo Civil de 1973 previa de forma genérica a participação desta figura em algumas hipóteses. No entanto, tal instituto ganhou maior importância a partir da entrada em vigor do Novo Código de Processo Civil haja vista que passou a dispor de um capítulo da Parte Geral exclusivamente dedicado ao tema.

A partir da introdução do art. 138 do Código de Processo Civil, no entender de Humberto Theodoro Jr. (2017, p. 409) restou determinado "a forma e os limites da intervenção do amicus curiae, em qualquer modalidade de processo, bem como regulando os respectivos poderes".

Dessa forma, é inegável o pensamento no sentido de que a introdução desta figura de forma específica no Novo Código de Processo Civil trouxe uma maior visibilidade e regulamentação no ordenamento brasileiro. 
O termo amicus curiae, usualmente é traduzido do latim para o português no sentido de "amigo do tribunal" ou "colaborador da Corte". Contudo, tal tradução pode passar uma interpretação errada desta figura. No entendimento de Cassio Scarpinella Bueno (2013, p. 45):

[...] é inócuo, porque vazio de significado para a experiência jurídica brasileira, traduzir a expressão amicus curiae para o vernáculo. Ela, mesmo quando traduzida, não tem referencial na nossa história jurídica e, por isso, fica carente de verdadeira identificação. É insuficiente a "tradução vernacular" daquela expressão; é mister encontrar o seu referencial e seu contexto de análise no direito brasileiro.

Dessa forma, no entender de Cassio Scarpinella Bueno (2013, p. 45), a expressão "amigo do tribunal" não permite que relacionemos tal contexto com os elementos do ordenamento brasileiro. Inclusive tal interpretação pode até levar a uma ideia errônea, já que o termo "amigo" encontra-se presente nos casos de suspeição de magistrados, auxiliares de justiça, testemunhas e de outros sujeitos imparciais do processo, conforme prevê o Código de Processo Civil em seus arts. 145, inc. I, art. 148, incs. I, II e III e art. $447, \S 3^{\circ}$, inc. I.

Além disso, conforme entendimento de DIDIER JR., FREDIE (2017, p. 588), não se pode haver a confusão entre a figura do amicus curiae com a do perito:

\footnotetext{
A intervenção do amicus curiae não se confunde com a participação do perito. A perícia é meio de prova, e, pois de averiguação do substrato fático. O perito é auxiliar do juízo. $\mathrm{O}$ amicus curiae, que é parte, dá a sua opinião sobre a causa, em toda a sua complexidade, sobretudo nas questões técnico-jurídicas. Além disso, não há honorários para o amicus curiae, nem se submete às regras de impedimento e suspeição.
}

Com base nas ideias acima expostas e de acordo com o entendimento proferido por Humberto Theodoro Jr. (2017, p. 408) é correto afirmar que a figura do amicus curiae tem como objetivo servir como um auxiliar do juízo, em situações nas quais esteja demonstrada a relevância social, a repercussão geral ou nos casos do objeto ser muito específico, de forma que, para que o magistrado melhor compreenda o tema, se faz necessária a manifestação técnica de pessoa da área.

Cabe ressaltar ainda o disposto no enunciado de n. 127 do Fórum Permanente de Processualistas Civis o qual informa: "A representatividade 
adequada exigida do amicus curiae não pressupõe a concordância unânime daqueles a quem representa".

É correto dizer, portanto, que a presença de amici curiae no processo contribui para que determinado caso particular seja analisado sob uma nova ótica ou ainda, sob uma ótica mais ampla. A participação de vários entes -seja como pessoa física ou como pessoa jurídica- é benéfica ao possibilitar a existência de diferentes argumentações e visões sobre o mesmo tema.

Este entendimento vai de acordo com o proferido por Fredie Didier Jr. (2017, p. 590) o qual entende que "a pluralidade de visões sobre o mesmo tema enriquece o debate e qualifica, necessariamente, a decisão judicial”.

Nesta linha de raciocínio Humberto Theodoro Jr. (2017, p. 410) ressalta que a participação do amicus curiae no processo permite a formação de um precedente judicial mais democrático, de forma que temas que apresentam repercussão social possam ter seus debates pluralizados.

Ademais, no sentido técnico de sujeito da lide objeto do processo, o amicus curiae não configura como parte propriamente dita do processo, porém pode solicitar sua participação em virtude de seu interesse jurídico na solução daquele caso ou ainda ser convocado a se manifestar sobre determinado assunto, atuando como colaborador do juízo. Para Humberto Theodoro Jr. (2017, p. 408) a atuação do amicus curiae, restringe-se a um caráter opinativo a respeito da matéria do objeto da demanda, no sentido de contribuir com o aprimoramento da tutela jurisdicional.

\section{$4 \quad$ NATUREZA JURÍDICA}

A natureza jurídica do amicus curiae caracteriza-se por ser tema de bastante controvérsia entre os doutrinadores. Humberto Theodoro Jr. (2017, p. 409) informa que existem entendimentos no sentido de qualificarem o amicus curiae como modalidade interventiva sui generis ou atípica - tendo em vista que sua intervenção somente poderá ocorrer se demonstrado o interesse jurídico no caso-, bem como entendimentos no sentido de tratar-se de terceiro que intervém no processo para servir de auxiliar ao juízo, servindo assim para fornecer elementos técnicos, contribuindo para um melhor entendimento do caso pelo magistrado. 
Neste sentido, Humberto Theodoro Jr. (2017, p. 410) informa que entende a figura do amicus curiae da seguinte maneira:

\begin{abstract}
é um auxiliar especial do juiz, a quem cabe fornecer informações técnicas reputadas relevantes para o julgamento da causa. Não se confunde, entretanto, com aqueles auxiliares que habitualmente participam do processo, tais como o escrivão, o perito, o tradutor, o curador, o custus legis etc., pois chega até a dispor do direito de recorrer em alguns casos. Sua interferência é, pois, típica e particularíssima, seja pelas condições em que se dá, seja pelo objetivo visado.
\end{abstract}

A controvérsia acerca da natureza jurídica do amicus curiae encontrava-se presente inclusive dentro do Supremo Tribunal Federal, sendo que em julgado do Pleno datado de 2015, foi proferido o seguinte entendimento:

Ementa: CONSTITUCIONAL E PROCESSUAL CIVIL. AMICUS CURIAE. PEDIDO DE HABILITAÇÃO NÃO APRECIADO ANTES DO JULGAMENTO. AUSÊNCIA DE NULIDADE NO ACÓRDÃO RECORRIDO. NATUREZA INSTRUTÓRIA DA PARTICIPAÇÃO DE AMICUS CURIAE, CUJA EVENTUAL DISPENSA NÃO ACARRETA PREJUÍZO AO POSTULANTE, NEM LHE DÁ DIREITO A RECURSO. 1. O amicus curiae é um colaborador da Justiça que, embora possa deter algum interesse no desfecho da demanda, não se vincula processualmente ao resultado do seu julgamento. É que sua participação no processo ocorre e se justifica, não como defensor de interesses próprios, mas como agente habilitado a agregar subsídios que possam contribuir para a qualificação da decisão a ser tomada pelo Tribunal. A presença de amicus curiae no processo se dá, portanto, em benefício da jurisdição, não configurando, consequentemente, um direito subjetivo processual do interessado. 2. A participação do amicus curiae em ações diretas de inconstitucionalidade no Supremo Tribunal Federal possui, nos termos da disciplina legal e regimental hoje vigentes, natureza predominantemente instrutória, a ser deferida segundo juízo do Relator. A decisão que recusa pedido de habilitação de amicus curiae não compromete qualquer direito subjetivo, nem acarreta qualquer espécie de prejuízo ou de sucumbência ao requerente, circunstância por si só suficiente para justificar a jurisprudência do Tribunal, que nega legitimidade recursal ao preterido. 3. Embargos de declaração não conhecidos." (ADI 3460-ED, rel. min. Teori Zavascki, Plenário, DJe de 11.03.2015) (grifo nosso)

Dessa forma, com base no entendimento jurisprudencial firmado pelo Supremo Tribunal Federal, pode-se afirmar que o amicus curiae pode ser qualificado como colaborador da justiça. Ademais, conforme consta 
informação proferida por Humberto Theodoro Jr. (2017, p. 410): “a natureza dessa participação no processo é "predominantemente instrutória", razão pela qual pode ser indeferida, segundo as conveniências da causa, sem que se reconheça legitimidade recursal ao preterido".

5

\section{O "AMICUS CURIAE" NO CONTROLE CONCENTRADO DE CONSTITUCIONALIDADE}

Segundo André Ramos Tavares (2018, p. 1216) no Brasil existe a junção de dois modelos: o modelo de controle concreto - o qual ocorre no exercício de determinado processo jurisdicional, sendo este difuso entre os juízes e tribunais-, e o controle abstrato o qual possui exclusividade de análise pelo Supremo Tribunal Federal. Em relação ao controle concreto, os efeitos são produzidos apenas interpartes, dependendo da Resolução do Senado Federal (conforme dispõe o art. 52, inc. $\mathrm{X}$ da $\mathrm{CF} / 88$ ) para eventualmente produzirem efeitos sociais gerais.

Agora no que se refere ao sistema concentrado de controle de constitucionalidade, tal processo ocorre com características diferentes do modelo difuso. Neste sentido, Eloísa Machado de Almeida (2015, p. 73) informa que deve ser feita uma análise em abstrato da norma que está sendo objeto de discussão e através de uma ação específica, tal questionamento será avaliado pelo órgão jurisdicional competente de forma a ser analisada a questão e a maneira com que esta afeta a Constituição.

Tendo em vista que este trabalho restringe-se a análise do amicus curiae pelo Supremo Tribunal Federal, em especial através do controle concentrado de constitucionalidade, torna-se necessária uma breve explanação sobre o controle de constitucionalidade e as possibilidade de intervenção do amicus curiae desta maneira.

É correto afirmar que muitas questões relativas ao controle de constitucionalidade encontram-se dispostas na Constituição Federal de 1988. Conforme entendimento de Eloísa Machado de Almeida (2015, p. 74) existem quatro tipos de ações específicas voltadas ao controle de constitucionalidade, sendo que dependendo da forma ou da ação utilizada isso implicará em um novo contorno pelo tribunal:

Assim, a depender da forma de controle - difuso ou concentrado - ou da via de ação utilizada, a questão constitucional levada ao tribunal assumirá diferentes 
contornos, o que impactará o alcance, a forma e os efeitos da decisão. (grifo nosso)

No Brasil, o controle de constitucionalidade concentrado pode ocorrer de acordo com as seguintes ações: ação direta de inconstitucionalidade, ação direta de inconstitucionalidade por omissão, ação declaratória de constitucionalidade e arguição de descumprimento de preceito fundamental.

Tanto a ADC, como a ADI e a ADPF possuem os seguintes efeitos: são via de regra, ex tunc, apresentam eficácia erga omnes e efeito vinculante em relação ao Judiciário e à Administração Pública. Ademais, os legitimados para propor as ações são os mesmos, conforme regulamenta o art. 103 da Constituição Federal.

No que se refere a figura do amicus curiae nas ações de controle abstrato de constitucionalidade é possível afirmar que ela se encontra estipulada nos art. $7^{\circ}, \S 2^{\circ}$ e art. 20 da Lei 9.868 de 10 de novembro de 1999 , bem como pelo art. $6^{\circ}$ da Lei n. 9.882 de 3 de dezembro de 1999, permitindo, dessa forma, o ingresso da referida figura nos processos acerca do controle concentrado de constitucionalidade, contudo, não estabeleceu detalhes a respeito de suas capacidades processuais.

Acerca deste tema, Eloísa Machado de Almeida (2015, p. 67) informa que o aspecto processual da figura do amicus curiae foi sendo construído a partir das discussões dos casos pelo tribunal e que, portanto, não se trata de um tema cujo os parâmetros estão totalmente delimitados e que não possam sofrer mudanças futuras.

Para Fredie Didier Jr. (2017, p. 879) a partir da presença destes artigos, tornou-se possível que o amicus curiae ingressasse no processo de forma espontânea desde que fosse demonstrado como que sua figura poderia contribuir para o entendimento de determinado caso.

De acordo com a ideia acima referida, Gilmar Mendes (2011, p. 218) informa que o art. $7^{\circ}, \S 2^{\circ}$ da Lei $9.868 / 99$ "confere um caráter pluralista ao processo objetivo de controla abstrato de constitucionalidade, permitindo que o Tribunal decida com pleno conhecimento dos diversos aspectos envolvidos na questão".

Além disso, na Emenda Regimental 29/2009, o Supremo Tribunal Federal estipulou em seu Regimento Interno (art. 13, inc. XVIII) artigo possível de ser aplicável aos amici curiae: 


\section{$[\ldots]$}

XIII - decidir de forma irrecorrível, sobre a manifestação de terceiros, subscrita por procurador habilitado, em audiências públicas ou em qualquer processo em curso no âmbito da Presidência.

De início, pairavam dúvidas quanto à possibilidade de admitir o ingresso de amicus curiae nas ações declaratórias de constitucionalidade, devido ao fato que os art. $7^{\circ}$, caput e o art. $18^{5}$ da Lei $9.868 / 99$ vetavam a figura.

Todavia, Eloísa Machado de Almeida (2015, p. 70) explica que o entendimento firmado pelo Supremo Tribunal Federal compreendeu que não existem empecilhos para que a figura do amicus curiae seja admitida nas ações declaratórias de constitucionalidade, desde que estejam presentes os critérios de relevância da matéria e representatividade dos postulantes, sendo aplicado por analogia o disposto no art. $7^{\circ}, \S 2^{\circ}$.

Neste sentido foi proferida a seguinte decisão monocrática realizada pela Ministra Ellen Gracie na ADC $14^{6}$ :

[...] é certo que a previsão de ingresso na causa, para manifestação, de outros órgãos e entidades encontra-se situada, na Lei 9.868/99, no capítulo que rege, especificamente, a tramitação das ações diretas de inconstitucionalidade (art. $7^{\circ}, \S 2^{\circ}$ ). Contudo, é inegável a estreita interconexão entre estas ações e as declaratórias de constitucionalidade. Ambas objetivam, em última análise, a verificação abstrata da compatibilidade de determinada norma com o ordenamento constitucional pátrio. Entendo, assim, perfeitamente possível a aplicação analógica do referido art. $7^{\circ}, \S 2^{\circ}$, da Lei $9.868 / 99$, às ações declaratórias de constitucionalidade, cuja natureza tanto se assemelha com a que possui a ação direta de inconstitucionalidade" (decisão proferida em 16 de dezembro de 2008).

Quanto à arguição de descumprimento de preceito fundamental, apesar desta se encontrar regulamentada de forma diferente das demais, conforme consta no art. $6^{\circ}, \S \S 1^{\circ}$ e $2^{\circ}$ da Lei $9.882 / 99$, o entendimento

\footnotetext{
${ }^{5}$ Lei 9.868, de 10 de novembro de 1999. Art. 18. Não se admitirá intervenção de terceiros no processo de ação declaratória de constitucionalidade.

$\S 1^{\circ}$ (VETADO)

$\S 2^{\circ}$ (VETADO)

${ }^{6}$ A decisão está disponível em www.stf.jus.br, sendo que foi consultado no dia 15 de fev. de 2019

${ }^{7}$ Lei 9.882/99, Art. $6^{\circ}$ Apreciado o pedido de liminar, o relator solicitará as informações às autoridades responsáveis pela prática do ato questionado, no prazo de dez dias.
} 
jurisprudencial atual entende que tal fato não impede a participação do amicus curiae nestes casos desde que os demais requisitos estejam preenchidos.

\title{
A TEORIA DA SOCIEDADE ABERTA E A RELAÇÃO COM A FIGURA DO AMICUS CURIAE
}

Compartilhando das ideias adotadas por Peter Haberle, o Ministro do Supremo Tribunal Federal Gilmar Mendes entende $(2008 / 2009$, p. 1) que no que diz respeito ao controle de constitucionalidade, se faz necessário a adoção de um modelo que possibilite que o Tribunal consiga, a partir de fatos expostos e documentos legais, chegarem a uma conclusão. Neste sentido, o modelo de "sociedade aberta" é de grande auxílio para o ingresso de diferentes grupos nos processos judiciais, servindo para integrar o Estado de Direito. Mais especificamente, no que se refere ao amicus curiae este instituto pode ser visto como muito importante, pois contribui para a qualidade da decisão jurisdicional. Neste sentido, Gilmar Mendes (2008/2009, p. 8) informa:

\begin{abstract}
Ao ter acesso a essa pluralidade de visões em permanente diálogo, o Supremo Tribunal Federal passa a contar com os benefícios decorrentes dos subsídios técnicos, implicações político-jurídicas e elementos de repercussão econômica que possam vir a ser apresentados pelos "amigos da Corte". Para Gilmar Mendes ${ }^{8}$, as ideias de Peter Haberle estão sendo aderidas no meio acadêmico, na produção legislativa e na jurisprudência brasileira, citando a possibilidade de ingresso como amicus curiae por meio da Lei $\mathrm{n}^{\circ}$ 9.868/99 como um exemplo.
\end{abstract}

Neste sentido, no que tange ao Supremo Tribunal Federal, Gilmar Mendes (2008/2009, p. 3) afirma que a possibilidade prevista pela Lei ${ }^{\circ}$ 9.868/99 permitiu que os magistrados possam utilizar de informações

$\S 1^{\circ}$ Se entender necessário, poderá o relator ouvir as partes nos processos que ensejaram a argüição, requisitar informações adicionais, designar perito ou comissão de peritos para que emita parecer sobre a questão, ou ainda, fixar data para declarações, em audiência pública, de pessoas com experiência e autoridade na matéria.

$\S 2^{\circ}$ Poderão ser autorizadas, a critério do relator, sustentação oral e juntada de memoriais, por requerimento dos interessados no processo.

${ }^{8}$ Cf. Gilmar Ferreira Mendes. O pensamento de Peter Haberle na jurisprudência do Supremo Tribunal Federal; Observatório da Jurisdição Constitucional. Brasília: IDP, ano 2, 2008/2009. ISSN $1982-4564$ 
técnicas para poderem se embasar em determinada questão, bem como possibilita que a participação de terceiros interessados seja algo possível.

Para André Puccinelli Jr. (2015, p. 116) é possível afirmar que ao existir o ingresso do amicus curiae para discutir questões de natureza constitucional, tal ato:

\begin{abstract}
[...] aproxima a Corte Constitucional da realidade circunjacente, pois traz à colação as dúvidas e os problemas que as questões constitucionais suscitam no meio comunitário, as preocupações das distintas facções sociais, os valores e os interesses em disputa, bem como a repercussão negativa ou positiva que a decisão final poderá acarretar sobre a própria sociedade.
\end{abstract}

Dessa forma, Peter Haberle (1997, p. 33) defende que a ampliação das pessoas que podem interpretar a norma é algo importante, pois se deve buscar a integração, mesmo que esta seja de forma mais indireta, da "res publica". Neste sentido, informa que, tendo em vista que a Constituição delimita e normatiza não apenas o Estado em sentido estrito, como também a esfera pública, aspectos da vida privada bem como a forma com que a sociedade deverá estar organizada, não é possível que as forças sociais e privadas sejam tratadas apenas como objetos, devendo possuir essa possibilidade de participação.

Por fim, Haberle (1997, p. 34) explica: "limitar a hermenêutica constitucional aos intérpretes "corporativos" ou autorizados jurídica ou funcionalmente pelo Estado significaria um empobrecimento ou um autoengodo".

Portanto, é nítida a importância conferida, durante o processo, não apenas para aqueles que naturalmente já o compõem, tais como advogados, magistrados e promotores, como também para a participação de terceiros, de modo que essa participação enriquece em muito o debate, além de pluralizá-lo, sempre tendo como parâmetro o disposto na Constituição.

\title{
7 DIFICULDADES ENFRENTADAS PELO AMICUS CURIAE DE MODO A ATINGIR DE FORMA MAIS EFICAZ SEU POTENCIAL DEMOCRÁTICO
}

Conforme entendimento de Virgílio Afonso da Silva (2006, p. 193) apesar de poder parecer uma tarefa simples, a análise da interpretação 
conforme a Constituição perante o Supremo Tribunal Federal pode aparentar-se um pouco dificultosa, não pela interpretação em si, mas pela divergência entre o que a doutrina e jurisprudência sustentam do que realmente é aplicado.

Em um sistema ideal, o ordenamento jurídico não apresenta influências externas, tais como por meio da política, de outros institutos ou mecanismos. A independência do órgão jurisdicional, no entendimento de Luís Roberto Barroso (2016, p. 223) vem inclusive garantida por meio de garantias institucionais -como é o caso da autonomia administrativa e financeira-, bem como garantias funcionais -tais como irredutibilidade de subsídios, vitaliciedade e inamovibilidade-. No entanto, o modelo ideal não é o mesmo que o modelo real, guardando certas diferenças nos casos concretos. No entendimento do Ministro Luís Roberto Barroso (2016, p. 225):

O modelo real, como não é difícil de intuir, terá uma dose razoável de cada uma das visões extremas descritas acima. O direito pode e deve ter uma vigorosa pretensão de autonomia em relação à política. Isso é essencial para a subsistência do conceito de Estado de direito e para a confiança da sociedade nas instituições judiciais. A realidade, contudo, revela que esta autonomia será sempre relativa. Existem razões institucionais, funcionais e humanas para que sejam assim. Decisões judiciais, com frequência, refletirão fatores extrajurídicos. Dentre eles, incluem-se os valores pessoais e ideológicos do juiz, assim como outros elementos de natureza política e institucional. [...]

Não obstante, além da dificuldade no sentido da decisão do magistrado muitas vezes refletir influências externas que podem prejudicar a qualidade do julgamento, outras dificuldades que a figura do amicus curiae apresenta residem no desconhecimento de grande parcela da população a respeito de sua figura - o que dificulta que a democratização se dê de forma mais efetiva-, bem como a necessidade de estar representado por advogado quando o amicus curiae atua de forma voluntária.

Além disso, a figura do amicus curiae não pode ser entendida como meio de protelar um julgamento, mas de enriquecê-lo, sendo assim, se faz extremamente necessário que sejam trazidos argumentos inovadores de modo a contribuir para a tomada de uma decisão jurisdicional que leve em conta os diferentes aspectos apresentados. 


\section{8}

\section{CONSIDERAÇÕES FINAIS}

Através do referido trabalho foi possível constatar que a figura do amicus curiae apresenta um importante caráter democrático, haja vista que possui o intuito de colaborar com o juízo de forma a trazer um maior leque argumentativo, de acordo com as experiências, vivências ou conhecimentos específicos que determinada pessoa (física ou jurídica) possua a respeito daquele tema.

Haja vista que o objeto de análise foi especificamente o Supremo Tribunal Federal, cabe dizer que a possibilidade de ingresso do amicus curiae é de extrema importância, já que muitos temas discutidos guardam não apenas divergências com relação aos seus posicionamentos, como também uma alta especificidade.

Cabe ressaltar ainda que muitos dos julgamentos ocorridos no Supremo Tribunal Federal, em especial os que dizem respeito ao controle concentrado de constitucionalidade, possuem discussões que permeiam e afetam não somente o "mundo jurídico", como também aspectos econômicos, sociais e políticos dos cidadãos como um todo.

No que tange as ações de controle de constitucionalidade este efeito é ainda mais evidente, devido o que for decidido poder ser aplicado a todos de forma indistinta. Além disso, em regra, os julgamentos ocorridos neste caso produzirão efeitos perpétuos.

Sob esse aspecto é nítido dizer que a interpretação do disposto na norma é de grande importância, porém deve ser sempre o ponto de partida e nunca a única e exclusiva interpretação possível. Neste sentido, a presença do amicus curiae se faz ainda mais valiosa por possibilitar que novas interpretações possam ser objeto de análise, sendo que esta ideia inclusive encontra-se de acordo com a idealizada por Peter Haberle acerca de uma Constituição aberta aos intérpretes.

Além disso, quando se fala em "aspecto democrático" isso não quer dizer, necessariamente, um alto número de pessoas - sejam elas físicas ou jurídicas- atuando em certo processo na condição de amicus curiae. Não é a intenção do Código de Processo Civil, e nem das demais normas que regulamentam a figura do amicus curiae, que estejam necessariamente presentes um alto número de pessoas. Dessa forma, a grande quantidade de terceiros no processo pode até ocorrer, mas não é ela em si que legitima ou possibilita uma melhor interpretação do fato objeto de discussão. 
$\mathrm{Na}$ realidade, quando se fala no "potencial democrático" do amicus curiae remete-se a possibilidade dos diferentes setores sociais que sejam afetados por aquela medida ou que possam nela contribuir de alguma forma (sendo através de conhecimentos técnicos ou experiências pessoais) possam ser ouvidos, mesmo que isso se dê de maneira indireta, como pode ser observado na atuação de pessoas jurídicas, ONGs ou entidades na condição de amicus curiae.

Este entendimento inclusive explica o motivo que, apesar de ser possível a participação de pessoas físicas na qualidade de amicus curiae, esta se dá de forma mais rara, sendo os requisitos de participação nestes casos analisados de forma mais minuciosa.

Não obstante, apesar deste viés democrático realmente existir na figura do amicus curiae, não é possível dizer que ela se efetiva nos dias atuais de forma plena, haja vista que muitas pessoas -sejam elas físicas ou jurídicas- desconhecem tal previsão legal, o que inviabiliza de certa forma seu potencial democrático.

Além disso, nas hipóteses admitidas do amicus curiae atuar de forma voluntária, existe a necessidade que esteja representada por advogado. Neste sentido, apesar de tal exigência ser justificável, é inegável dizer que também impede que o potencial democrático seja atingido de forma completa ao criar uma barreira financeira e formal.

Por fim, a figura do amicus curiae não pode ser entendida como meio de protelar um julgamento, mas de enriquecê-lo, sendo assim, se faz extremamente necessário que sejam trazidos argumentos inovadores de modo a contribuir para a tomada de uma decisão jurisdicional que leve em conta os diferentes aspectos apresentados.

\section{REFERÊNCIAS BIBLIOGRÁFICAS}

ALMEIDA, Eloísa Machado. O amicus curiae no Supremo Tribunal Federal. 2015. Tese (Doutorado em Direitos Humanos) - Faculdade de Direito da Universidade de São Paulo, São Paulo, 2015. Disponível em: https://bdpi.usp.br/item/002767758. Acesso em: 01 jan. 2019.

BARROSO, Luís Roberto. O controle de constitucionalidade no direito brasileiro: exposição sistemática da doutrina e análise crítica da jurisprudência. São Paulo: Saraiva, 2016. 
BARROSO, Luís Roberto. Curso de Direito Constitucional Contemporâneo: os conceitos fundamentais e a construção de um novo modelo. 5 ed. São Paulo: Saraiva, 2015 .

BRASIL. [Constituição (1988)]. Constituição da República Federativa do Brasil. São Paulo: Revista dos Tribunais, 2000.

BRASIL. Código de Processo Civil. 21ª ed. São Paulo: Saraiva, 2016.

BUENO, Cassio Scarpinella; Amicus curiae no processo civil brasileiro: um terceiro enigmático. São Paulo: Saraiva, 2006

BUENO, Cassio Scarpinella. Comentários ao Código de Processo Civil: art. $1^{\text {o }}$ a 317 Parte Geral. São Paulo: Saraiva, 2017.

CABRAL, Antonio do Passo. Pelas asas de Hermes: a intervenção do amicus curiae, um terceiro especial. Revista Direito Administrativo, Rio de Janeiro, v. 234, p. 111-141, out/dez. 2003; Disponível em:

http://bibliotecadigital.fgv.br/ojs/index.php/rda/article/view/45149. Acesso em: 04 set. 2019.

CAMPOS, Carlos Alexandre de Azevedo. Dimensões do Ativismo Judicial do STF. Rio de Janeiro: Forense, 2014.

CAVALCANTE, Márcio André Lopes. A decisão do Relator que ADMITE ou INADMITE o ingresso do amicus curiae é irrecorrível. Dizer o Direito. Brasília: 17 de out. de 2018. Disponível em: https://www.dizerodireito.com.br/2018/10/a-decisao-dorelator-que-admite-ou.html\#more. Acesso em: 19 fev. 2019.

COUTO, Monica Bonetti; SILVA, Guilherme Amorim Campos da. Amicus curiae, modelo processual democrático e o Novo Código de Processo Civil. Revista Eletrônica de Direito Processual - REDP, v. 18, n. 3, p. 256-276, set./dez. 2017. Disponível em: https://www.e-publicacoes.uerj.br/index.php/redp/article/view/29311/22431. Acesso em: 15 ago. 2019.

DEL PRÁ, Carlos Gustavo Rodrigues. Amicus curiae: instrumento de participação democrática e de aperfeiçoamento da prestação jurisdicional. Curitiba: Juruá, 2011.

DIDIER JR., Fredie; Curso de Direito Processual Civil: volume 1; Editora Juspodivm; 2017;

DIDIER JR., Fredie; SOUZA, Marcus Seixas. Formação do precedente e amicus curiae no direito imperial brasileiro: o interessante Dec. 6.142/1876. Revista de Processo, v. 220, p. 407-424, jun. 2013. 
FIGUEIREDO, Apoliana Rodrigues. Amicus curiae: estudo do artigo 138 do Novo Código de Processo Civil. Revista Pensamento Jurídico, v. 11, n. 2, julho/dez de 2017. Disponível em:

https://fadisp.com.br/revista/ojs/index.php/pensamentojuridico/article/view/108. Acesso em: 18 ago. 2019

GAIA, Fausto Siqueira. O povo como guardião da Constituição: estudo da legitimidade do controle preventivo de constitucionalidade realizado pela Corte constitucional brasileira.

Revista de Informação Legislativa, a. 51, n. 202, p. 145-157, abr./jun. 2014. Disponível em:

http://www2.senado.leg.br/bdsf/bitstream/handle/id/503042/001011322.pdf?sequence=1 .

Acesso em: 04 set. 2019.

HASWANI, Mariângela Furlan. A comunicação estatal como garantia de direitos: foco no Brasil, na Colômbia e na Venezuela. 2010. Tese (Pós-Graduação em Integração da América Latina da Universidade de São Paulo) - Faculdade de Direito da Universidade de São Paulo, São Paulo, 2019. Disponível em:

http://www.teses.usp.br/teses/disponiveis/84/84131/tde-31082012-

122619/publico/2010_MariangelaFurlanHaswani.pdf. Acesso em: 31 julh. 2010.

KOCHEVAR, Steven. Amici Curiae in Civil Law Jurisdictions. The Yale Law Journal, n. 122, p. 1653-1669, 2013. Disponível em:

https://www.yalelawjournal.org/pdf/1158_hvj33ruz.pdf. Acesso em: 30 julh. 2019.

LEAL, Mônia Clarrisa Henning. Jurisdição constitucional aberta: a abertura constitucional como pressuposto de intervenção do amicus curiae no direito brasileiro. DPU, Brasília, n. 21, p. 27-49, mai./jun. 2008. Disponível em:

http://dspace.idp.edu.br:8080/xmlui/bitstream/handle/123456789/578/Direito\%20Publico $\% 20$ 212008_Monica\%20Clarissa\%20Hennig\%20Leal.pdf?sequence=1. Acesso em: 04 set. 2019.

MENDES, Gilmar Ferreira. O pensamento de Peter Haberle na jurisprudência do Supremo Tribunal Federal. Observatório da Jurisdição Constitucional. Brasília, a. 2, p. 1-33, 2008/2009. Disponível em:

https://portal.idp.emnuvens.com.br/observatorio/article/download/205/173. Acesso em: 13 ago. 2019.

MENDES, Gilmar Ferreira. Estado de Direito e Jurisdição Constitucional: 2002/2010. São Paulo: Saraiva, 2011

NASCIMENTO, Valéria Ribas do; MORAIS, Jose Luis Bolzan de. A (des)utopia da liberdade e igualdade: possibilidade de sentido para construção de jurisdições constitucionais democráticas. Revista de Informação Legislativa, a. 46, n. 182, p. 155 176, abr./jun. 2009. Disponível em:

https://www2.senado.leg.br/bdsf/bitstream/handle/id/496914/RIL182.pdf?sequence=1\#pa ge $=156$. Acesso em: 04 set. 2019. 
PUCCINELLI JÚNIOR, André. Curso de direito constitucional. 5 ed. São Paulo:

Saraiva, 2015.

SILVA, Vírgilio Afonso da. Interpretação conforme a Constituição: entre a trivialidade e a centralização judicial. Revista Direito GV, v. 2, n. 1, p. 191-210, jan./jun. 2006.

Disponível em: https://direitosp.fgv.br/publicacoes/revista/artigo/interpretacao-conformeconstituicao-entre-trivialidade-centralizacao-judi. Acesso em: 01 de ago. de 2019.

TAVARES, André Ramos. Curso de Direito Constitucional. $16^{\mathrm{a}}$ ed. São Paulo: Saraiva Educação, 2018.

THEODORO JÚNIOR, Humberto. Curso de Direito Processual Civil: volume $1.57^{\mathrm{a}}$ ed. Rio de Janeiro: Editora Forense, 2017. 